\title{
The regulation of oxytocin and oxytocin receptor in human placenta according to gestational age
}

\author{
Seung-Chul Kim,*, Jae-Eon Lee2,*, Seong Soo Kang³, Hoe-Saeng Yang4, \\ Sun Suk Kim¹ and Beum-Soo An²
}

'Department of Obstetrics and Gynecology, Biomedical Research Institute, Pusan National University School of Medicine, Pusan, Korea

${ }^{2}$ Department of Biomaterials Science, College of Natural Resources and Life Science/Life and Industry Convergence Research Institute, Pusan National University, Pusan, Korea

3Department of Veterinary Surgery, College of Veterinary Medicine, Chonnam National University, Gwangju, Korea ${ }^{4}$ Department of Obstetrics and Gynecology, Medical College, Dongguk University, Jung-gu, Korea

*(S-C Kim and J-E Lee contributed equally to this work)

Correspondence should be addressed to B-S An

Email

anbs@pusan.ac.kr

\begin{abstract}
Oxytocin (OXT) is a peptide hormone that plays a central role in the regulation of parturition and lactation. OXT signaling is mediated by OXT receptor (OXTR), which shows species- and tissue-specific expressions and gene regulation. In the present study، we examined the synthesis of OXT and OXTR in human placenta tissue according to gestational age. A total of 48 placentas were divided into early preterm, late preterm and term groups depending on gestational age, and expression of OXT and OXTR was evaluated. First, OXT and OXTR mRNA and protein were detected in normal placenta tissue via Q-PCR, Dot-blot and Western blot assay. Both OXT and OXTR levels in normal placenta increased gradually in the late stage of pregnancy, suggesting that local OXT may play a critical role in the function of the placenta. To determine the regulatory mechanism of OXT, placental BeWo cells were administrated estrogen $\left(E_{2}\right)$ or progesterone $\left(\mathrm{P}_{4}\right)$, and expression of OXT and OXTR was tested. The mRNA and protein levels of OXT and OXTR were upregulated by $\mathrm{E}_{2}$ but blocked by co-treatment with $\mathrm{P}_{4}$. In order to confirm the estrogen receptor (ESR)-mediated signaling, we administrated ESR antagonists together with $E_{2}$ to BeWo cells. As a result, both OXT and OXTR were significantly altered by ESR1 antagonist (MPP) while moderately regulated by ESR2 antagonist (PHTPP). These results suggest that OXT and OXTR are controlled mainly by $\mathrm{E}_{2}$ in the placenta via ESR1 and thus may play physiological functions in the human placenta during the late stage of pregnancy.
\end{abstract}

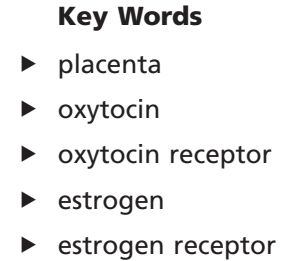

Journal of Molecular Endocrinology (2017) 59, 235-243

\section{Introduction}

The placenta is a transient tissue that performs many functions for the maintenance of pregnancy. In humans, the specific structure of the placenta is apparent as early as 21 weeks of pregnancy (Benirschke et al. 1998). During pregnancy, the placenta is uniquely organized for exchange of nutrients, oxygen, hormones, antibodies and http://jme.endocrinology-journals.org DOI: 10.1530/JME-16-0223
C) 2017 Society for Endocrinology Printed in Great Britain
Published by Bioscientifica Ltd. 
waste products between the mother and fetus and may transfer valuable information for the pregnancy (Sood et al. 2006). These functions are realized by bringing maternal and fetal blood into close apposition (Enders \& Blankenship 1999).

The placenta also performs hormonal functions in both maternal and fetal circulation to affect pregnancy, metabolism, fetal growth and parturition (Gude et al. 2004). Placental hormones such as human chorionic gonadotropin (hCG), progesterone $\left(\mathrm{P}_{4}\right)$ and estradiol $\left(\mathrm{E}_{2}\right)$ are important for pregnancy maintenance. Detection of hCG in the urine and blood is commonly used as a pregnancy test, as it is only produced during pregnancy (Cole 2012). $\mathrm{P}_{4}$ is also a crucial hormone for gestational maintenance. From 6-8 weeks of gestation until the end of pregnancy, the placenta gradually becomes the main source of $\mathrm{P}_{4}$ (Tuckey 2005). $\mathrm{P}_{4}$, which has multiple functions throughout the gestational period, acts on the endometrium to promote uterine quiescence and inhibits myometrium contractility. In other organs, $\mathrm{P}_{4}$ prepares mammary glands for lactation by increasing proliferation of the mammalian epithelium, while at the same time, preventing lactation until labor by inhibiting prolactin secretion (Pang \& Hartmann 2007).

During the first weeks of gestation, $\mathrm{E}_{2}$ is mainly produced by the corpus luteum, after which the placenta synthesizes this steroid. The effects of $\mathrm{E}_{2}$ are typically controlled by the activation of nuclear estrogen receptors, estrogen receptor 1 (ESR1) and estrogen receptor 2 (ESR2). In the placenta, ESR1 expression is normally confined to the cytotrophoblast, whereas ESR2 is more highly expressed in the syncytiotrophoblast (Bukovsky et al. 2003, Bechi et al. 2006). The concentration of $\mathrm{E}_{2}$ increases by as much as 80 -fold during pregnancy (Bukovsky et al. 2003). The role of $E_{2}$ in gestation is extremely varied, from promoting growth of the endometrium and preparing the uterus for implantation to bringing about maternal cardiovascular adaptations (Magness \& Rosenfeld 1989, Burton et al. 1999, Albrecht et al. 2000, King \& Critchley 2010). $E_{2}$ also causes angiogenesis and vasodilatation in the placental tissue, which indicates a role in the regulation of human utero-placental blood flow (Costa 2016).

Oxytocin (OXT) is a nanopeptide hormone that plays many roles in physiological processes, including those related to reproduction such as maternal behavior, labor, lactation and ejaculation (Bethlehem et al. 2013). OXT is synthesized by magnocellular neurons of supraoptic and paraventricular nuclei of the hypothalamus, whose axons terminate within the posterior lobe of the pituitary gland
(Arrowsmith \& Wray 2014). OXT is also synthesized by peripheral tissues, including the uterus, corpus luteum, amnion and placenta (Arrowsmith \& Wray 2014). OXT signaling is mediated by oxytocin receptor (OXTR), which is involved in the rhodopsin-type $G$ protein-coupled receptor family (Sladek \& Song 2012). OXTR is coupled to phospholipase $\mathrm{C}$, which commands the synthesis of diacylglycerol (DAG) and inositol 1,4,5-trisphosphate. Consequently, after the activation of OXTR, inositol triphosphate causes an increase in $\mathrm{Ca}^{2+}$ influx from both intracellular and extracellular stores, whereas DAG prompts the activation of protein kinase type $\mathrm{C}$, which phosphorylates target proteins (Koehbach et al. 2013). Although the physiological functions and signaling pathway of OXT have been established in other organs such as the brain, uterus and mammalian gland, there are limited studies available in the placenta. Furthermore, although OXT synthesis was tested in the rat placenta, OXT signaling has never been examined in the human placenta, which has different morphogenesis and endocrine function from rat (Lefebvre et al. 1992).

In this study, we examined the local synthesis of OXT and expression of OXTR in the human placenta according to gestational age. Regulation of OXT and OXTR by sex steroid hormones $\mathrm{E}_{2}$ and $\mathrm{P}_{4}$ was also explored in human placental BeWo cells.

\section{Materials and methods}

\section{Tissue and plasma collection and processing}

This study was approved by the Institutional Review Board of the Pusan National University Hospital Clinical Trial Center (H-1302-005-015), and all participants gave written informed consent. Placental tissue and plasma samples were obtained from pregnant women who met the following inclusion criteria: (1) singleton pregnancy, (2) normal pregnancy at the time of sample collection and (3) healthy women with no preexisting clinical conditions such as diabetes, hypertension or autoimmune disease. The placental samples were divided into early preterm $(n=10,2$ were from vaginal delivery and 8 were from C-section), late preterm $(n=18,6$ were from vaginal delivery and 12 were from C-section) and term $(n=20,3$ were from vaginal delivery and 17 were from C-section) groups after onset of labor as indicated in the previous study (Kim et al. 2016). The early preterm period was determined to be 22-29 weeks of gestation, which is clinically important since preterm delivery frequently occurs during this period, whereas the late preterm period was determined http://jme.endocrinology-journals.org DOI: 10.1530/JME-16-0223
๑) 2017 Society for Endocrinology Printed in Great Britain
Published by Bioscientifica Ltd 
Table 1 Clinical characteristics of pregnancies.

\begin{tabular}{l} 
\\
\hline Gestational age (weeks) \\
Birth weight $(\mathrm{g})$ \\
Systolic BP $(\mathrm{mmHg})$ \\
Diastolic BP $(\mathrm{mmHg})$ \\
Parity \\
Gravidity \\
BMI $\left(\mathrm{kg} / \mathrm{m}^{2}\right)$
\end{tabular}

\begin{tabular}{c}
\hline Early preterm $(n=10)$ \\
\hline $27.5 \pm 4.7$ \\
$887.0 \pm 312.5$ \\
$111.0 \pm 11.0$ \\
$73.0 \pm 8.2$ \\
$0.6 \pm 1.0$ \\
$2.4 \pm 1.3$ \\
$23.1 \pm 2.6$
\end{tabular}

\begin{tabular}{c}
\hline Late preterm $(n=18)$ \\
\hline $34.2 \pm 8.2$ \\
$2316.1 \pm 570.7$ \\
$107.8 \pm 8.1$ \\
$67.8 \pm 8.1$ \\
$0.7 \pm 0.8$ \\
$2.5 \pm 1.5$ \\
$25.7 \pm 3.4$
\end{tabular}

\begin{tabular}{c}
\hline Term $(n=20)$ \\
\hline $38.4 \pm 1.1$ \\
$3167.0 \pm 268.8$ \\
$108.0 \pm 7.7$ \\
$68.5 \pm 7.5$ \\
$0.7 \pm 0.6$ \\
$2.2 \pm 1.0$ \\
$25.0 \pm 1.6$
\end{tabular}

to be 30-36 weeks of gestation. The term placenta group was collected from a gestational age of 37-40 weeks. The plasma samples were collected at the 1st stage of labor and stored until the experiment. The clinical characteristics of sample groups are shown in Table 1.

\section{Cell culture and treatments}

The BeWo human choriocarcinoma-derived cell line was cultured in Dulbecco's modified Eagle medium (DMEM, Hyclone, Logan, UT, USA) containing 10\% fetal bovine serum (FBS, Hyclone) and 1\% streptomycin/penicillin (Welgene Inc., Seoul, Korea) and grown in $5 \% \mathrm{CO}_{2}$ at $37^{\circ} \mathrm{C}$. In order to mitigate the effect of endogenous steroids, cells were cultured in phenol red-free medium containing $5 \%(\mathrm{v} / \mathrm{v})$ charcoal dextran-stripped serum (DMEM-5\%CD, Hyclone) for 2 days. The experimental treatment (ethanol as control; $10-7$ and $10-{ }^{5} \mathrm{M}^{-}$of $\mathrm{E}_{2}$ and $\mathrm{P}_{4}$, respectively, alone or in combination with equivalent concentrations of each compound) was performed in triplicate wells. The experiments were repeated at least three times independently. Cells were harvested $24 \mathrm{~h}$ after treatment to measure mRNA and protein levels.

To examine the signaling of $\mathrm{E}_{2}$ in combination with certain receptors, cells were treated with $10-{ }^{6} \mathrm{M}$ of selective ESR1 and ESR2 antagonists: 1,3-Bis(4-hydroxyphenyl)-4methyl-5-[4-(2-piperidinylethoxy)phenol]- $1 H$-pyrazole dihydrochloride (MPP, Tocris Bioscience, MO, USA) and 4-[2-phenyo-5,7-bis(trifluoromrthyl)pyrazolo(1,5-a) pyrimidin-3-yl]phenol (PHTPP, Tocris Bioscience), respectively, in DMEM for $24 \mathrm{~h}$.

\section{Measure of blood OXT concentration}

Blood was collected from each volunteer and collected in a plastic tube under aseptic conditions with EDTA as an anti-coagulant and then centrifuged in order to separate plasma. Plasma was stored at $-70^{\circ} \mathrm{C}$, and the sample was slowly thawed at room temperature before the experiment. Plasma OXT concentrations were measured using an oxytocin-ELISA kit (ADI-900-153A-0001; Enzo Life Sciences, NY, USA) following the manufacturer's protocol. The ELISA kit is highly sensitive (minimal detection levels $<11.7 \mathrm{pg} / \mathrm{mL}$ OXT) and specific. The interand intra-assay coefficients of variation were $<10 \%$ and $11.9 \%$ for OXT.

\section{Quantitative real-time PCR}

Total RNA was extracted using TRIzol reagent (Invitrogen Co., Carlsbad, CA, USA) according to the manufacturer's instructions. Total RNA concentration was measured using a spectrophotometer. First-strand complement DNA (cDNA) was synthesized by reverse transcription from $3 \mu \mathrm{g}$ of total RNA using moloney murine leukemia virus (MMLV) reverse transcriptase (Invitrogen Co.) and random primers (9-mers; TaKaRa Bio Inc., Otsu, Shiga, Japan). Quantitative real-time PCR (Q-PCR) was performed with cDNA template $(2 \mu \mathrm{L})$ and $2 \times$ Power SYBR Green $(6 \mu \mathrm{L}$; ТОYОВО Co., Osaka, Japan)-containing specific primers. Primer sequences for $\beta$-actin (control gene), OXT, OXTR and placental leucine aminopeptidase (P-LAP) are shown in Table 2. Q-PCR was carried out for 40 cycles using the following parameters: denaturation at $95^{\circ} \mathrm{C}$ for $15 \mathrm{~s}$, followed by annealing and extension at $70^{\circ} \mathrm{C}$ for $60 \mathrm{~s}$. Fluorescence intensity was measured at the end of the extension phase of each cycle. The threshold value for the fluorescence intensity of all samples was set manually. The reaction cycle at which PCR products exceeded this fluorescence intensity threshold during the exponential phase of PCR amplification was considered to be the threshold cycle (CT). Quantification was performed by comparing $\mathrm{CT}$ values at constant fluorescence intensity. The amount of transcript is inversely related to the observed CT, and for every 2-fold dilution of the transcript, the CT is expected to increase by one increment. Relative expression (R) was calculated using the equation $\mathrm{R}=2-(\Delta \mathrm{CT}$ sample $-\Delta \mathrm{CT}$ control). To identify a normalized arbitrary value for each gene, each value obtained was normalized to the expression

Published by Bioscientifica Ltd. 
Table 2 Primer sequences for real-time PCR analyses.

\begin{tabular}{ll}
\hline Gene name & Primer \\
\hline$\beta$-actin & Forward \\
OXT & Reverse \\
& Forward \\
OXTR & Reverse \\
& Forward \\
& Reverse
\end{tabular}

Sequence $\left(5^{\prime}-3^{\prime}\right)$

GGACTTCGAGCAAGAGATGG

AGCACTGTGTTGGCGTACAG

GCTGCCAGGAGGAGAACTAC

GTGTTCGGAGCCATCAAGTT

TTCTTCGTGCAGATGTGGAG

GGAGGAGTTGCTCTTTTTGC of $\beta$-actin, a ubiquitous housekeeping gene for placenta tissue. $\beta$-actin is one of the cytoskeletal actins that are involved in cell motility, structure and integrity. $\beta$-actin is an attractive candidate for reference coamplification because it exhibits only minor intraindividual kinetic changes and is not primarily affected by any human disease (Kreuzer et al. 1999).

\section{Western blotting analysis}

Protein samples were extracted with Pro-prep solution (iNtRON Biotechnology, Seoul, Korea) following the manufacturer's protocol. Cytosolic proteins $(25 \mu \mathrm{g})$ were separated by $10 \%$ sodium dodecyl sulfate polyacrylamide gel electrophoresis (SDS-PAGE) and transferred to nitrocellulose membranes (Daeillab Service Co., Seoul, Korea). The membranes were then blocked for $2 \mathrm{~h}$ with $5 \%$ skim milk (Difco, Sparks, MD, USA) in Tris-buffered saline (TBS)with 0.05\% Tween20 (TBS-T). After blocking, membranes were incubated with anti-OXTR goat (SC8102, Santa Cruz Biotechnology, diluted 1:500) overnight, followed by HRP-conjugated anti-goat secondary antibody (SC-2020, Santa Cruz Biotechnology, diluted 1:2000) in $5 \%$ skim milk with TBS-T for $1 \mathrm{~h}$. Luminol reagent (BioRad) was used to visualize antibody binding. Each blot was then stripped by incubation with $2 \%$ SDS and $100 \mathrm{mM}$ mercaptoethanol in $62.5 \mathrm{mM}$ Tris- $\mathrm{HCl}$ (pH 6.8) for $30 \mathrm{~min}$ at $50-60^{\circ} \mathrm{C}$. The membranes were subsequently probed with antibody against $\beta$-actin (\#4967, Cell Signaling Technology, diluted 1:2000) as an internal control. The antibodies for OXTR (Young et al. 2014) and $\beta$-actin (Li et al. 2013) were selected based on previous publication. The blots were scanned using Gel Doc 1000, version 1.5 (Bio-Rad), and band intensities were normalized to $\beta$-actin levels.

\section{Dot-blotting analysis}

Cytosolic proteins $(0.5 \mu \mathrm{g})$ were transferred onto a nitrocellulose membrane by using a Slot Blot kit
(Pharmacia Biotech, CA, USA). The membranes were then blocked for 30 min with $5 \%$ skim milk with TBS-T. After blocking, membrane was incubated with antiOXT mouse (MAB5296, Merck Millipore, diluted1:5000) for $1 \mathrm{~h}$ at room temperature. The antibody for OXT was chosen based on the previous report (Kohno et al. 2008). After being washed three times with TBS-T, the membrane was incubated with HRP-conjugated anti-mouse secondary antibody (SC-2005, Santa Cruz Biotechnology, diluted 1:2000) in 5\% skim milk with TBS-T for $1 \mathrm{~h}$. OXT proteins were then normalized with $\beta$-actin, visualized and detected by same methods with Western blotting.

\section{Immunohistochemical staining}

Placental tissues were fixed with $10 \%$ formalin and embedded in paraffin. Sections (4- $\mu$ m thick) were then cut, deparaffinized in xylene and hydrated in descending grades of ethanol. Endogenous peroxidase activity was blocked with $3 \%$ hydrogen peroxide $\left(\mathrm{H}_{2} \mathrm{O}_{2}\right)$ in methanol. After eliminating non-specific reactions by incubation with $2 \%$ bovine serum albumin (BSA) for $20 \mathrm{~min}$, sections were incubated at room temperature for $2 \mathrm{~h}$ with antibodies against OXT (1:50) or OXTR (1:200), which were same as used for Western/dotblot analysis. The sections were washed with TBS-T, followed by incubation with second antibody for $1 \mathrm{~h}$ at $37^{\circ} \mathrm{C}$. Detection of primary antibody was performed with a Polink-2 Plus HRP DAB kit (GBI Labs, Mukilteo, WA, USA). Images of tissue were captured at $40 \times$ using a model BX50F-3 optical microscope (Olympus, Tokyo, Japan).

\section{Data analysis}

Results are presented as the mean \pm standard deviation (S.D.). Data were analyzed by $t$-test using Sigma Plot 10.0 (Systat Software, Inc, San Jose, Calif). $P$ values $<0.05$ were considered statistically significant. http://jme.endocrinology-journals.org DOI: 10.1530/JME-16-0223
๑) 2017 Society for Endocrinology Printed in Great Britain
Published by Bioscientifica Ltd. 


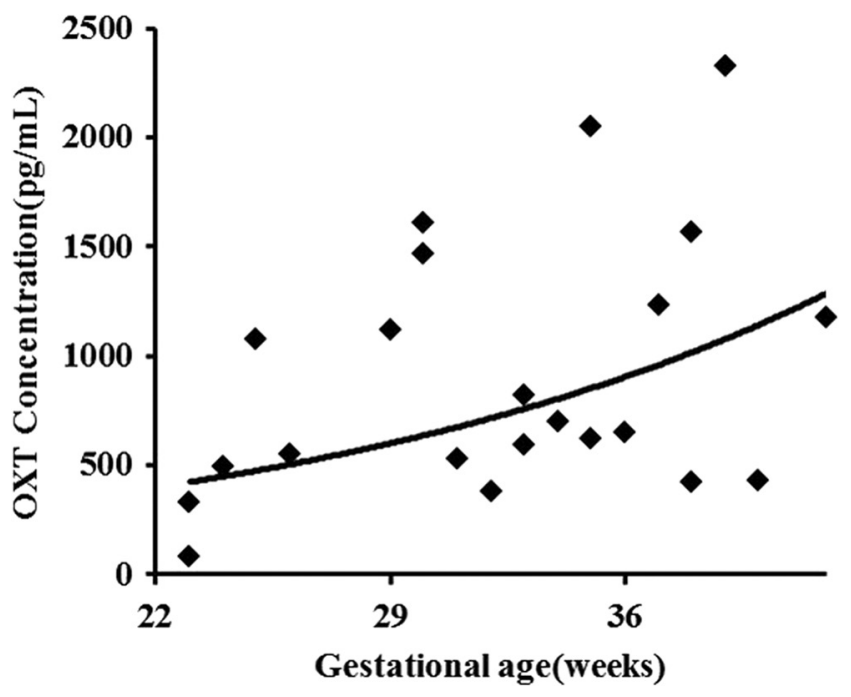

Figure 1

Plasma OXT concentration according to gestational age. Plasma OXT concentration $(\mathrm{pg} / \mathrm{mL})$ was measured and represented.

\section{Results}

\section{Plasma oxytocin concentration and its metabolic enzyme according to gestational age}

For the initial experiment, plasma OXT concentration during gestation was examined. The plasma samples were acquired from 23 normal pregnant women, and OXT levels were measured from gestational age between 22 and 40 weeks. The concentration of OXT ranged from 80 to $2324 \mathrm{pg} / \mathrm{mL}$ with a median value of $918 \mathrm{pg} / \mathrm{mL}$. OXT plasma concentrations increased gradually from 22 week until the late stage of pregnancy (Fig. 1). The average values of OXT concentration were 607, 941 and $1.189 \mathrm{pg} / \mathrm{mL}$ in early preterm, late preterm and term periods, respectively. Expression of the metabolic enzyme of OXT in the placenta, $P-L A P$, showed no significant difference during gestation (data not shown).

\section{Expression of OXT and OXTR in placenta according to gestational age}

For the next experiment, we measured mRNA expression levels of OXT and OXTR in the placenta by Q-PCR. As shown in Fig. 2A and B, mRNA levels of both $O X T$ and OXTR significantly increased in the term placenta against early preterm placenta by 3.3- and 4.5-fold, respectively, which were gestational age dependent. Protein levels of OXT and OXTR were also analyzed by Dot-blot and Western blot assays. We performed Dot-blot assay rather than Western blot to detect OXT protein due to its low molecular weight. The results show that OXT and OXTR
A

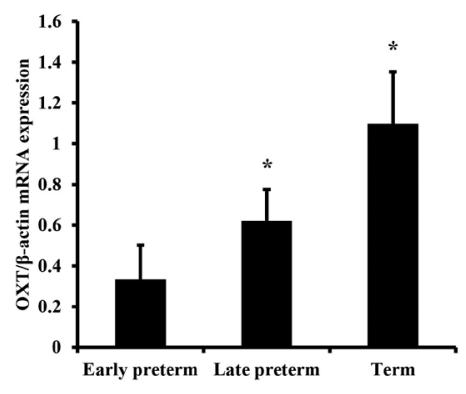

C

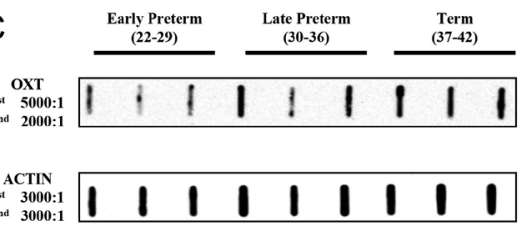

$E$

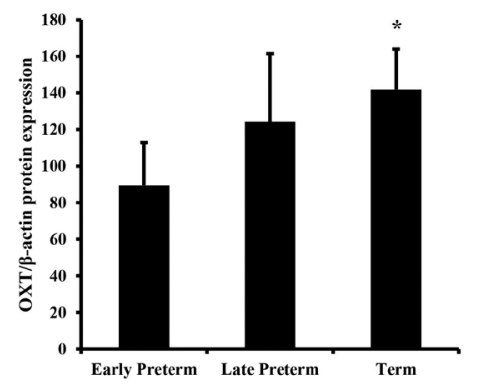

B
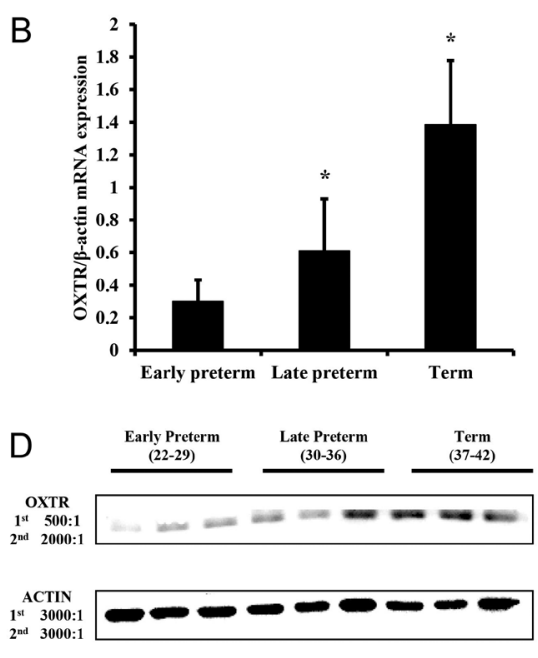

F

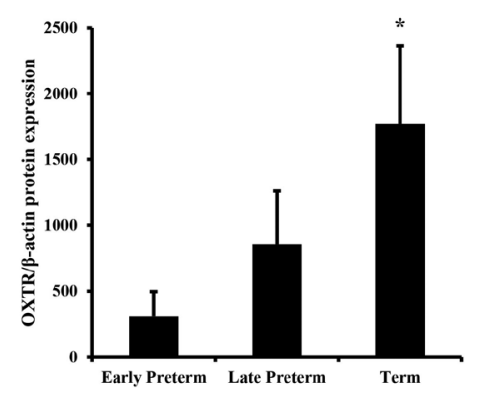

Figure 2

The mRNA and protein levels of OXT and OXTR in the human placenta according to gestational age. Total mRNA and proteins were harvested from the human placenta after the onset of labor. Transcriptional levels of OXT (A) and OXTR (B) were analyzed by Q-PCR depending on gestational age. Proteins were processed for Dot-blot assay and Western blot assay and quantified for graphs, and the representative samples are shown in (C) and (D). The values for OXT (E) and OXTR (F) are represented as schematic graphs. Total mRNA and protein expression levels were normalized to that of $\beta$-actin. Data were expressed as the mean \pm S.D. ${ }^{*} P<0.05$ compared to the early preterm group. http://jme.endocrinology-journals.org DOI: 10.1530/JME-16-0223
() 2017 Society for Endocrinology Printed in Great Britain 
protein levels gradually increased until the late stage of pregnancy (Fig. 2C and D). These results were consistent with those of mRNA. The bands of $\beta$-actin were used as an internal standard in both the Dot-blot and Western blot to normalize the data.

\section{Immunohistochemical analysis of OXT and OXTR in the human placenta}

To further explore the localization of OXT and OXTR proteinsin placentaltissues, we performedimmunostaining for OXT and OXTR. The placenta is basically composed of cytotrophoblasts and syncytiotrophoblasts. As shown in Fig. 3A, OXT was detected in both cytotrophoblasts and syncytiotrophoblasts, whereas OXTR signals were dominantly localized to syncytiotrophoblasts than cytotrophoblasts.

\section{The regulation of OXT and OXTR in placental BeWo cells}

In order to examine the regulation of OXT and OXTR gene expression, human choriocarcinoma-derived BeWo cells were employed. The two main sex steroid hormones, $\mathrm{E}_{2}$ and $\mathrm{P}_{4}$, were administrated to BeWo cells at concentrations of $10-{ }^{7} \mathrm{M}$ and $10-{ }^{5} \mathrm{M}$. The mRNA expression levels of OXT and OXTR were upregulated by 3.3- and 4.5-fold, respectively, whereas co-treatment of $\mathrm{P}_{4}$ reduced the stimulation to the control levels (Fig. 4). Protein analysis of OXT by dot-blotting showed strong intensity possibly due to background signals from non-specific binding of total proteins (data not shown). Single treatment with $\mathrm{P}_{4}$ did not significantly modulate the expression of genes. Since the actions of $\mathrm{E}_{2}$ are classically mediated by its cognitive receptors, ESR1 and ESR2, inhibitors of ESR isoforms were further tested. BeWo cells were pretreated with MPP (ESR1 antagonist) or PHTPP (ESR2 antagonist) before $\mathrm{E}_{2}$, and expression levels of OXT and OXTR were examined (Fig. 5). In the results, effects of $\mathrm{E}_{2}$ on OXT (Fig. 5A) and OXTR (Fig. 5B) were completely blocked by MPP, whereas PHTPP moderately reduced the increase.

\section{Discussion}

OXT is normally produced in the hypothalamus and stored in the posterior pituitary gland. However, OXT is also synthesized by peripheral tissues, including the corpus luteum, uterus lining, testes and amnion. It has also been reported that OXT is produced and secreted from placental tissue (Sakai et al. 1993). Although a
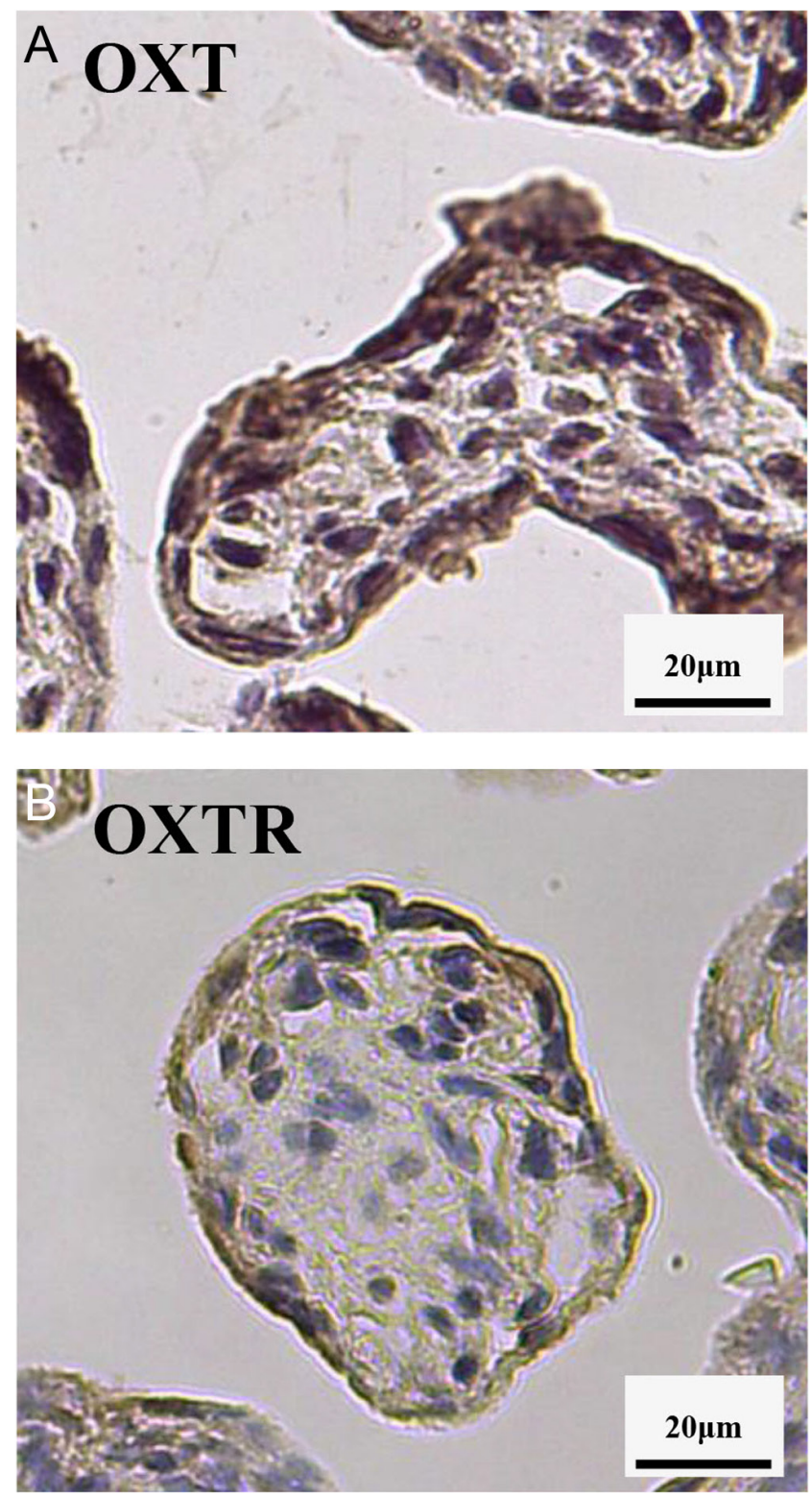

Figure 3

Immunostaining of OXT and OXTR in human placental tissue. To examine localization of each protein, tissues were stained with specific antibodies for OXT (A) and OXTR (B). A full color version of this figure is available at http://dx.doi.org/10.1530/JME-16-0223.

high concentration of OXT is associated with labor and regulation of uterine contractions, this action is only limited at the term period (Sugimoto et al. 1997). However, the physiological function of OXT during early- to midstage of pregnancy is not understood.

In this study, we examined the local production of OXT and its regulation in human placenta. It is known that OXT levels in the blood increase during pregnancy (Thornton et al. 1992, Veiga et al. 2015), which was also

Published by Bioscientifica Ltd. 

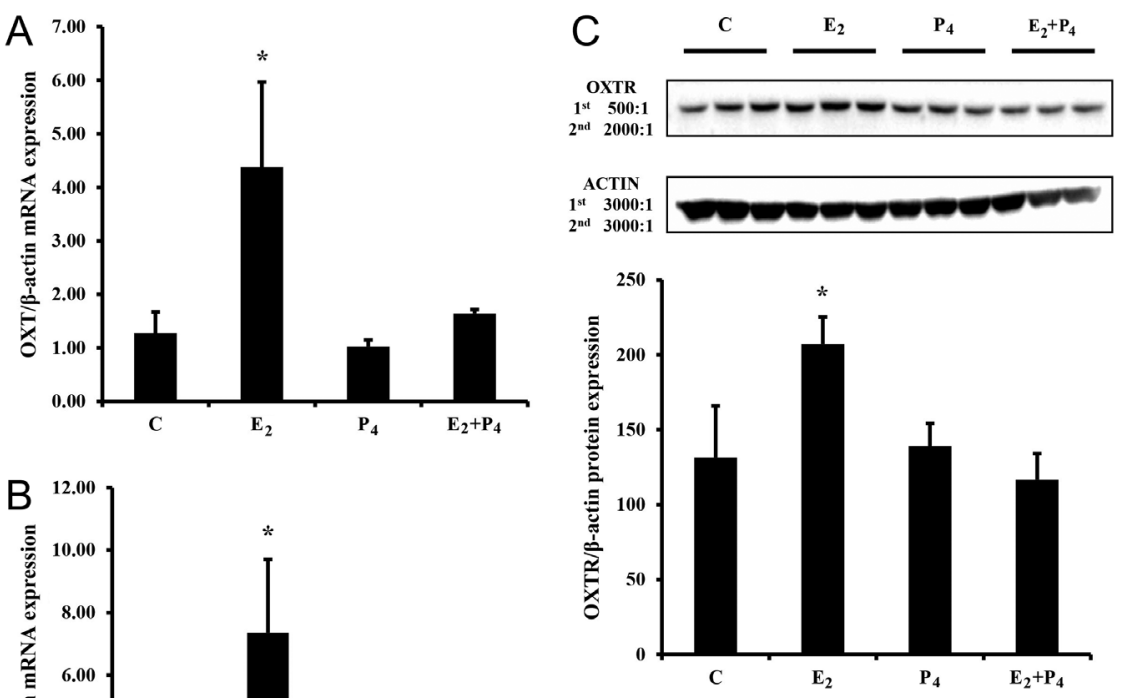

Figure 4

Regulating OXT and OXTR expression levels by $\mathrm{E}_{2}$ in BeWo cells. After treatment of BeWo cells with $E_{2}, P_{4}$, and $E_{2}+P_{4}, m R N A$ and proteins were harvested. Transcriptional levels of OXT (A) and OXTR (B) were analyzed by Q-PCR. Translational levels of OXTR (C) were analyzed by Western blot assay. Total mRNA and protein expression levels were normalized to that of $\beta$-actin. Data were expressed as the mean \pm s.D. ${ }^{*} P<0.05$ compared to the control group.

confirmed in our ELISA results. Peripheral existence of OXT has been confirmed in several tissues. In 1993, a cDNA clone of OXT was separated from rat and human uterine tissues and verified by Northern blot analysis (Lefebvre et al. 1993, Sakai et al. 1993). Although many studies have reported the synthesis of OXT in the uterus, there have been few studies regarding OXT in the placenta. In this study, transcriptional and translational levels of
OXT and OXTR in the placenta were increased at late stage of gestation. Because the endogenous OXT can be metabolized by the P-LAP enzyme in the placental tissue, we analyzed the expression of P-LAP. In the results, the expression levels of P-LAP were not significantly altered during gestational stage, suggesting that the amount of OXT is not regulated by P-LAP in the placenta. Previously, it was reported that OXT mRNA levels in the human
A
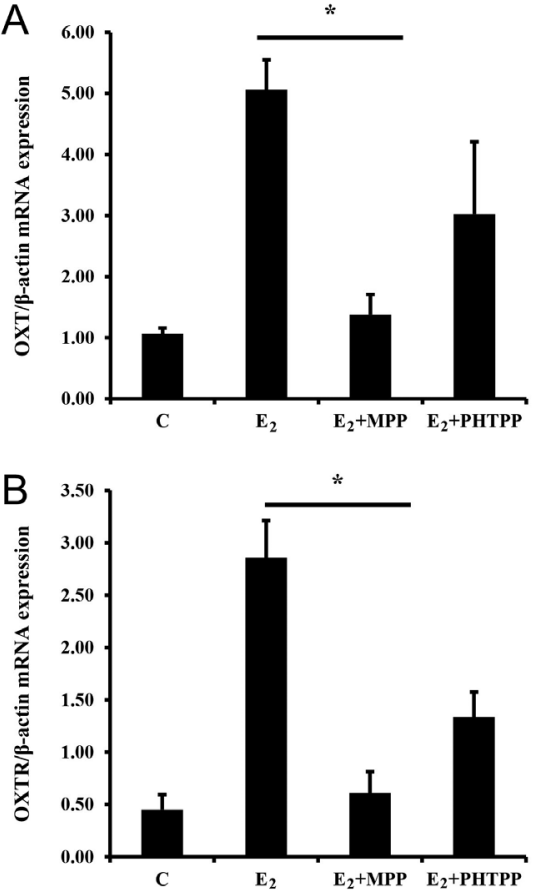
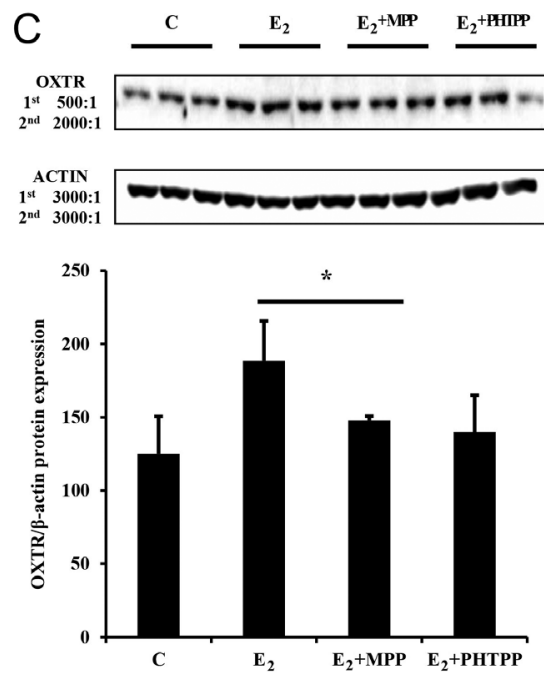

Figure 5

Effects of ESR antagonists on $E_{2}$-induced OXT and OXTR expression. After treatment of BeWo cells with $\mathrm{E}_{2}$ alone or ESR antagonists, mRNA and proteins were harvested. The transcriptional levels of OXT (A) and OXTR (B) were analyzed by Q-PCR. Translational levels of OXTR (C) were analyzed by Western blot assay. Total mRNA and protein expression levels were normalized to that of $\beta$-actin. Data were expressed as the mean \pm s.D. $* P<0.05$ compared to the $E_{2}$-treated group. 
chorio-decidua greatly increased at the start of labor (Nakazawa et al. 1984).

It has been well known that $\mathrm{E}_{2}$ and $\mathrm{P}_{4}$ are high in the plasma at late pregnancy (Johansson 1969, Loriaux et al. 1972). Since the expressions of OXT and OXTR were enhanced during the late stage of pregnancy, we hypothesized that $\mathrm{E}_{2}$ and/or $\mathrm{P}_{4}$ might be potent regulatory factors for OXT and OXTR expression. To prove this, placental BeWo cells were treated with $\mathrm{E}_{2}$ and/ or $\mathrm{P}_{4}$, and expression of OXT and OXTR was tested. In the results, OXT and OXTR mRNA and protein levels were upregulated by $\mathrm{E}_{2}$ but not by $\mathrm{P}_{4}$. Augmentation of OXT by $\mathrm{E}_{2}$ was also detected in the uterus, ovaries and neurohypophysis previously (Amico et al. 1981. Shukovski et al. 1990). Chibbar and coworkers demonstrated that OXT is synthesized within human amnion, chorion and decidua during late gestation and the expression of OXT in chorio-decidua was stimulated by $\mathrm{E}_{2}$ (Chibbar et al. 1995). For the next experiment, we verified the involvement of ESR isoforms in the regulation of OXT and OXTR. When BeWo cells were pretreated with MPP and PHTPP before $\mathrm{E}_{2}$, the ESR1-specific inhibitor, MPP, completely blocked the regulation of both OXT and OXTR, suggesting that the effect of $\mathrm{E}_{2}$ was dominantly mediated by ESR1. Involvement of ESR in the regulation of uterine OXT was also reported previously (Kimura et al. 1996), and the author demonstrated that OXT regulation by $\mathrm{E}_{2}$ is mediated by ESR1, which is similar with our data.

In conclusion, our results indicate that OXT and OXTR were highly expressed in the placenta during the late stage of pregnancy compared with early preterm. The local production of OXT and OXTR in the placenta was regulated by $\mathrm{E}_{2}$ but not by $\mathrm{P}_{4}$ via mainly ESR1, and thus, may play physiological functions in the human placenta during the late stage of pregnancy.

\section{Declaration of interest}

The authors declare that there is no conflict of interest that could be perceived as prejudicing the impartiality of the research reported.

\section{Funding}

This study was supported by a Biomedical Research Institute Grant (2015-09), Pusan National University Hospital.

\section{Author contribution statement}

B S An and S C Kim initiated and designed the study and played a role in recruitment of patients and sample collection. J E Lee contributed toward acquisition of data. B S An, J E Lee, S C Kim, S S Kang, H S Yang and S S Kim were involved in the analysis and interpretation of the data. $J \mathrm{E}$ Lee drafted the manuscript. All authors contributed to the revision of the manuscript and approval of the final draft.

\section{References}

Albrecht ED, Aberdeen GW \& Pepe GJ 2000 The role of estrogen in the maintenance of primate pregnancy. American Journal of Obstetrics and Gynecology 182 432-438. (doi:10.1016/S0002-9378(00)70235-3)

Amico JA, Seif SM \& Robinson AG 1981 Oxytocin in human plasma: correlation with neurophysin and stimulation with estrogen*. Journal of Clinical Endocrinology and Metabolism 52 988-993. (doi:10.1210/jcem-52-5-988)

Arrowsmith S \& Wray S 2014 Oxytocin: its mechanism of action and receptor signalling in the myometrium. Journal of Neuroendocrinology 26 356-369. (doi:10.1111/jne.12154)

Bechi N, Ietta F, Romagnoli R, Focardi S, Corsi I, Buffi C \& Paulesu L 2006 Estrogen-like response to p-nonylphenol in human first trimester placenta and BeWo choriocarcinoma cells. Toxicological Sciences 93 75-81. (doi:10.1093/toxsci/kfl043)

Benirschke K, Kaufman P \& Qumsiyeh MB 1998 Pathology of the Human Placenta. International Journal of Gynecologic Pathology $\mathbf{1 7}$ 93. (doi:10.1097/00004347-199801000-00020)

Bethlehem RA, van Honk J, Auyeung B \& Baron-Cohen S 2013 Oxytocin, brain physiology, and functional connectivity: a review of intranasal oxytocin fMRI studies. Psychoneuroendocrinology 38 962-974. (doi:10.1016/j.psyneuen.2012.10.011)

Bukovsky A, Cekanova M, Caudle MR, Wimalasena J, Foster JS, Henley DC \& Elder RF 2003 Expression and localization of estrogen receptor-alpha protein in normal and abnormal term placentae and stimulation of trophoblast differentiation by estradiol. Reproductive Biology and Endocrinology 1 b19. (doi:10.1186/1477-7827-1-19)

Burton GJ, Jauniaux E \& Watson AL 1999 Maternal arterial connections to the placental intervillous space during the first trimester of human pregnancy: the Boyd collection revisited. American Journal of Obstetrics and Gynecology 181 718-724. (doi:10.1016/S0002-9378(99)70518-1)

Chibbar R, Wong S, Miller F \& Mitchell B 1995 Estrogen stimulates oxytocin gene expression in human chorio-decidua. Journal of Clinical Endocrinology and Metabolism 80 567-572. (doi:10.1210/jc.80.2.567)

Cole LA 2012 hCG, the wonder of today's science. Reproductive Biology and Endocrinology 10 24. (doi:10.1186/1477-7827-10-24)

Costa MA 2016 The endocrine function of human placenta: an overview. Reproductive BioMedicine Online 32 14-43. (doi:10.1016/j.rbmo.2015.10.005)

Enders AC \& Blankenship TN 1999 Comparative placental structure. Advanced Drug Delivery Reviews 38 3-15. (doi:10.1016/S0169-409X(99)00003-4)

Gude NM, Roberts CT, Kalionis B \& King RG 2004 Growth and function of the normal human placenta. Thrombosis Research $\mathbf{1 1 4}$ 397-407. (doi:10.1016/j.thromres.2004.06.038)

Johansson ED 1969 Plasma levels of progesterone in pregnancy measured by a rapid competitive protein binding technique. Acta Endocrinologica 61 607-617. (doi:10.1210/jc.80.2.567)

Kim SC, Park M-N, Lee YJ, Joo JK \& An B-S 2016 Interaction of steroid receptor coactivators and estrogen receptors in the human placenta. Journal of Molecular Endocrinology 56 239-247. (doi:10.1530/JME-15-0248).

Kimura T, Takemura M, Nomura S, Nobunaga T, Kubota Y, Inoue T, Hashimoto K, Kumazawa I, Ito Y \& Ohashi K 1996 Expression of oxytocin receptor in human pregnant myometrium. Endocrinology 137 780-785. (doi:10.1210/endo.137.2.8593830)

King AE \& Critchley HO 2010 Oestrogen and progesterone regulation of inflammatory processes in the human endometrium. Journal of http://jme.endocrinology-journals.org

DOI: 10.1530/JME-16-0223
() 2017 Society for Endocrinology Printed in Great Britain
Published by Bioscientifica Ltd 
Steroid Biochemistry and Molecular Biology 120 116-126. (doi:10.1016/j.jsbmb.2010.01.003)

Koehbach J, Stockner T, Bergmayr C, Muttenthaler M \& Gruber CW 2013 Insights into the molecular evolution of oxytocin receptor ligand binding. Biochemical Society Transactions $\mathbf{4 1}$ 197-204. (doi:10.1042/BST20120256)

Kohno D, Nakata M, Maejima Y, Shimizu H, Sedbazar U, Yoshida N, Dezaki K, Onaka T, Mori M \& Yada T 2008 Nesfatin-1 neurons in paraventricular and supraoptic nuclei of the rat hypothalamus coexpress oxytocin and vasopressin and are activated by refeeding. Endocrinology 149 1295-1301. (doi:10.1210/en.2007-1276)

Kreuzer K-A, Lass U, Landt O, Nitsche A, Laser J, Ellerbrok H, Pauli G, Huhn D \& Schmidt CA 1999 Highly sensitive and specific fluorescence reverse transcription-PCR assay for the pseudogene-free detection of $\beta$-actin transcripts as quantitative reference. Clinical Chemistry 45 297-300.

Lefebvre DL, Giaid A \& Zingg H 1992 Expression of the oxytocin gene in rat placenta. Endocrinology 130 1185-1192. (doi:10.1210/en.130.3.1185)

Lefebvre DL, Lariviere R \& Zingg HH 1993 Rat amnion: a novel site of oxytocin production. Biology of Reproduction 48 632-639. (doi:10.1095/biolreprod48.3.632)

Li B, Shi Y, Shu J, Gao J, Wu P \& Tang S-J 2013 Wingless-type mammary tumor virus integration site family, member $5 \mathrm{~A}$ (Wnt5a) regulates human immunodeficiency virus type 1 (HIV-1) envelope glycoprotein 120 (gp120)-induced expression of pro-inflammatory cytokines via the $\mathrm{Ca} 2+/$ calmodulin-dependent protein kinase II (CaMKII) and c-Jun N-terminal kinase (JNK) signaling pathways. Journal of Biological Chemistry $\mathbf{2 8 8}$ 13610-13619. (doi:10.1074/jbc.M112.381046)

Loriaux DL, Ruder H, Knab D \& Lipsett M 1972 Estrone sulfate, estrone, estradiol and estriol plasma levels in human pregnancy. Journal of Clinical Endocrinology \& Metabolism 35 887-891. (doi:10.1210/jcem-35-6-887)

Magness RR \& Rosenfeld CR 1989 Local and systemic estradiol-17 beta: effects on uterine and systemic vasodilation. American Journal of Physiology: Endocrinology and Metabolism 256 E536-E542.

Nakazawa K, Makino T, Iizuka R, Kohsaka S \& Tsukada Y 1984 Immunohistochemical study on oxytocin-like substance in the human placenta. Endocrinologia Japonica 31 763-768. (doi:10.1507/endocrj1954.31.763)

Pang WW \& Hartmann PE 2007 Initiation of human lactation: secretory differentiation and secretory activation. Journal of Mammary Gland Biology and Neoplasia 12 211-221. (doi:10.1007/ s10911-007-9054-4)

Sakai A, Makino T, Kato Y, Kato T, Motoyatna S, Saito S, Iizuka R \& Nozawa S 1993 A uterine muscle contractile substance obtained from a human placental cDNA library. Gynecological Endocrinology $\mathbf{7}$ 77-82. (doi:10.3109/09513599309152484)

Shukovski L, Fortune JE \& Findlay JK 1990 Oxytocin and progesterone secretion by bovine granulosa cells of individual preovulatory follicles cultured in serum-free medium. Molecular and Cellular Endocrinology 69 17-24. (doi:10.1016/0303-7207(90)90084-L)

Sladek CD \& Song Z 2012 Diverse roles of G-protein coupled receptors in the regulation of neurohypophyseal hormone secretion. Journal of Neuroendocrinology 24 554-565. (doi:10.1111/ j.1365-2826.2011.02268.x)

Sood R, Zehnder JL, Druzin ML \& Brown PO 2006 Gene expression patterns in human placenta. PNAS 103 5478-5483. (doi:10.1073/pnas.0508035103)

Sugimoto Y, Yamasaki A, Segi E, Tsuboi K, Aze Y, Nishimura T, Oida H, Yoshida N, Tanaka T \& Katsuyama M 1997 Failure of parturition in mice lacking the prostaglandin F receptor. Science $\mathbf{2 7 7}$ 681-683. (doi:10.1126/science.277.5326.681)

Thornton S, Davison JM \& Baylis PH 1992 Plasma oxytocin during the first and second stages of spontaneous human labour. Acta Endocrinologica 126 425-429. (doi:10.1530/acta.0.1260425)

Tuckey RC 2005 Progesterone synthesis by the human placenta. Placenta 26 273-281. (doi:10.1016/j.placenta.2004.06.012)

Veiga G, Milazzotto M, Nichi M, Lúcio C, Silva L, Angrimani D \& Vannucchi C 2015 Gene expression of estrogen and oxytocin receptors in the uterus of pregnant and parturient bitches. Brazilian Journal of Medical and Biological Research 48 339-343. (doi:10.1590/1414-431X20143969)

Young KA, Liu Y, Gobrogge KL, Wang H \& Wang Z 2014 Oxytocin reverses amphetamine-induced deficits in social bonding: evidence for an interaction with nucleus accumbens dopamine. Journal of Neuroscience 34 8499-8506. (doi:10.1523/JNEUROSCI.4275-13.2014)

Received in final form 29 June 2017

Accepted 7 July 2017

Accepted Preprint published online 10 July 2017 http://jme.endocrinology-journals.org DOI: $10.1530 / \mathrm{JME}-16-0223$
C) 2017 Society for Endocrinology Printed in Great Britain
Published by Bioscientifica Ltd. 